\title{
Unique Postsynaptic Signaling at the Hair Cell Efferent Synapse Permits Calcium to Evoke Changes on Two Time Scales
}

\author{
T. S. Sridhar, ${ }^{1,2}$ M. C. Brown, ${ }^{1,2,3}$ and W. F. Sewell1,2,4 \\ ${ }^{1}$ Department of Otolaryngology, Eaton-Peabody Laboratory, Massachusetts Eye and Ear Infirmary, Boston, \\ Massachusetts 02114-3096, 2Department of Otology and Laryngology, Harvard Medical School, Boston, Massachusetts \\ 02115, 3Harvard-MIT Division of Health Sciences and Technology, Cambridge, Massachusetts 02139, and 4The \\ Program in Neurosciences, Harvard Medical School, Boston, Massachusetts 02115
}

\begin{abstract}
The cholinergic efferent fibers to the outer hair cells (OHCs) of the mammalian cochlea suppress sound-evoked activity of the auditory nerve on two time scales via one nicotinic receptor. A rapid action (tens of milliseconds) is responsible for modulating auditory nerve responses to acoustic stimulation. A slower action (tens of seconds) may protect the ear from acoustic overstimulation. The rapid action is likely caused by calcium influx through the nicotinic receptor that leads to opening of calcium-activated potassium $\left(\mathrm{K}_{\mathrm{Ca}}\right)$ channels, but the mechanism of the slower action has not been explained. To investigate this mechanism, we perfused the cochlea with agents that alter intracellular calcium release and uptake. Both fast and slow effects were enhanced by perfusion of the cochlea with ryanodine, an agonist of calcium-induced calcium release
\end{abstract}

(ClCR). Antagonists of sarcoplasmic/endoplasmic reticulum calcium ATPase (SERCA), cyclopiazonic acid, and thapsigargin (1) selectively enhanced the magnitude of slow effects, (2) prevented the diminution of slow effects with continued efferent stimulation, and (3) spread the range of frequencies over which slow effects were observed. We propose that the slow effect is attributable to release of calcium from the subsurface cisterna of the $\mathrm{OHC}$, perhaps triggered by $\mathrm{CICR}$ from the synaptic cisterna; the two time scales of efferent action may result from the unique arrangement of the two cisternae in the baso-lateral region of the $\mathrm{OHC}$.

Key words: cochlea; outer hair cell; cyclopiazonic acid; subsurface cisterna; ryanodine; acetylcholine
In the mammalian cochlea, outer hair cells (OHCs) work in concert with inner hair cells to provide the sharply tuned responses to acoustic stimuli seen in auditory nerve fibers. It is believed that the OHCs amplify the sound-evoked motion of the basilar membrane (for review, see Dallos, 1992). The afferent input to the brain is mostly from the inner hair cells, whereas the OHCs receive a prominent efferent innervation from the brainstem that is predominantly cholinergic (for review, see Warr, 1992). Electrical stimulation of the olivocochlear (OC) efferent fibers suppresses sound-evoked afferent discharge within $100 \mathrm{msec}$ (Galambos, 1956). This fast effect is thought to arise from the hyperpolarization of OHCs, which decreases their amplification of basilar membrane motion, and hence decreases stimulation of the inner hair cells. Recently, we have reported an additional slower suppression of sound-evoked auditory nerve activity that is also efferent-mediated (Sridhar et al., 1995). This slow effect has a much longer time course, building up and dissipating over tens of seconds. Whereas the fast effects modulate the coding of acoustic information by the cochlea, the slow effect may have an additional action of protecting the OHCs from trauma attributable to acoustic overstimulation (Reiter and Liberman, 1995).

The molecular basis of the fast effect is known to be a hyper-

\footnotetext{
Received July 12, 1996; revised Oct. 15, 1996; accepted Oct. 15, 1996.

This work was supported by grants from the National Institute on Deafness and Other Communication Disorders. We thank our colleagues, especially J. Guinan, M. C. Liberman, and E. A. Mroz, for helpful discussions and comments on earlier versions of this manuscript.

Correspondence should be addressed to Dr. William F. Sewell, Eaton-Peabody Laboratory, Massachusetts Eye and Ear Infirmary, 243 Charles Street, Boston, MA 02114-3096.

Copyright (C) 1996 Society for Neuroscience $0270-6474 / 96 / 170428-10 \$ 05.00 / 0$
}

polarizing $\mathrm{K}^{+}$current via calcium-activated potassium $\left(\mathrm{K}_{\mathrm{Ca}}\right)$ channels situated at the synapse (Housley and Ashmore, 1991; Kakehata et al., 1993; Erostegui et al., 1994; Blanchet et al., 1996). The $\mathrm{K}_{\mathrm{Ca}}$ channels are triggered by the brief entry of external calcium through an ionotropic nicotinic receptor (Fuchs and Murrow, 1992; Blanchet et al., 1996) that contains the recently cloned $\alpha 9$ subunit (Elgoyhen et al., 1994). Despite its slower time course, the slow effect also is mediated by the action of ACh on the same nicotinic receptor (Sridhar et al., 1995).

To circumvent the intrinsic inaccessibility and fragility of cochlear structures, we have taken an in vivo pharmacological approach to test hypotheses of signaling mechanisms that generate the slow effect in OHCs. The experiments in this study were designed to specifically examine how activation of a single receptor could lead to fast and slow effects that differ in their temporal profiles by three orders of magnitude. Two important considerations directed our search toward calcium-dependent mechanisms. First, the OC fast effect is mediated by calcium entry through the receptor, and hence calcium could be the trigger for the slow effect; second, the OHC contains a network of subsurface cisternae, whose homology to the endoplasmic reticulum (ER) suggests that it might serve as a reservoir of calcium.

Our hypothesis is that the slow effect is generated by calcium release from the subsurface cisternae along the baso-lateral cell membrane of the $\mathrm{OHC}$, and calcium activates $\mathrm{K}_{\mathrm{Ca}}$ channels to hyperpolarize the OHC. The entry of calcium via the nicotinic receptor could generate fast (milliseconds) effects by directly activating $\mathrm{K}_{\mathrm{Ca}}$ channels at the synapse and could also trigger calcium release from the synaptic cisterna, which in turn could set up calcium sparks or similar elementary events (Bootman and 
Berridge, 1995) that spread to the subsurface cisternae to evoke the slow effect. Thus, calcium entry via the nicotinic receptor may activate events on two widely varying time scales by exploiting the morphological specialization in the baso-lateral region of the $\mathrm{OHC}$.

\section{MATERIALS AND METHODS}

In our preparation, efferent fibers to the cochlea were electrically stimulated in the brainstem while responses reflecting the summed activity of hair cells and auditory nerve fibers were recorded from the inner ear (Brown et al., 1983; Gifford and Guinan, 1983, 1987). Albino guinea pigs of both sexes, weighing between 350 and $600 \mathrm{gm}$, were anesthetized with urethane ( $1.5 \mathrm{~g} / \mathrm{kg}$, i.p.), droperidol $(2 \mathrm{ml} / \mathrm{kg}$, i.m.), and fentanyl $(2 \mathrm{ml} / \mathrm{kg}$, i.m.). The animals received boosters of urethane (one-third the original dose) after 6-8 hr and boosters of droperidol and fentanyl (one-third the original dose) every $2 \mathrm{hr}$. Animals were tracheostomized and connected to a respirator. The temperature within the experimental chamber was maintained at $34^{\circ}-35^{\circ} \mathrm{C}$. The rectal temperature of the animal was maintained between $37^{\circ}$ and $39^{\circ} \mathrm{C}$. The pinnae were removed, and the cochlea was exposed by a dorsolateral approach. Acoustic stimuli were produced by a 1 " condenser microphone driven as a sound source and housed in a brass coupler that sealed tightly around the cartilaginous portion of the external ear (Kiang et al., 1965).

To measure the compound action potential (CAP) and cochlear microphonic $(\mathrm{CM})$, gross electric potentials that represent the summed activity of the auditory nerve fibers and the OHCs, respectively, a silver wire electrode was placed near the round window, and an indifferent electrode was placed in the neck muscles. Responses to acoustic stimuli (see below) were amplified 10,000 times by an AC-coupled amplifier (passband $100-10,000 \mathrm{~Hz}$ ). The resulting signal was digitized with a 30 $\mu$ sec sampling interval via a 12 bit A/D converter (National Instruments A2000), and the digital waveforms were averaged on-line using custom software in LabVIEW 2 (National Instruments) on a Macintosh computer. Each CAP data point plotted on the figures in this paper represents an average of eight responses. A posterior craniotomy was performed, and a portion of the cerebellum was aspirated to expose the floor of the fourth ventricle. The olivocochlear bundle (OCB) was stimulated electrically with electrodes placed on the floor of the fourth ventricle at the midline, where the OCB runs close to the surface of the brainstem (White and Warr, 1983). The stimulator consisted of a rake of six fine, silver wires placed at $0.5 \mathrm{~mm}$ intervals. After placement of the rake along the brainstem midline, different pairs of electrodes were assayed to find the optimum pair for eliciting OC activity. Shocks were always monophasic pulses of $150 \mu \mathrm{sec}$ duration. Shock levels were typically set 5-10 dB above threshold for facial twitches in the absence of the paralytic. Because electrical stimulation of the OCB can cause muscle twitches, muscle paralysis was induced with d-tubocurarine $(1.25 \mathrm{mg} / \mathrm{kg}$, i.m.) and maintained with boosters as necessary. OCB-induced changes in CM and CAPs were determined from digitized waveforms. Acoustic stimuli were clicks (100 $\mu \mathrm{sec}$ duration) or tone pips (4 msec duration; $0.5 \mathrm{msec}$ rise-fall times, $\cos ^{2}$ shaping, and were typically presented at $20-30 \mathrm{~dB}$ above visual detection threshold for the CAP).

Drugs were perfused through the scala tympani of the cochlea. An inlet perfusion hole was drilled in the cochlea just apical to the round window with a $0.25 \mathrm{~mm}$, hand-held pivot drill. After an additional ventral opening was made in the bulla, an outlet perfusion hole in the apex of the cochlea was pricked with a right-angle pick. The perfusion pipette (a 31 gauge, stainless-steel cannula) was placed in the basal hole and artificial perilymph composed of (in $\mathrm{mM}$ ): $120 \mathrm{NaCl}, 3.5 \mathrm{KCl}, 1.5 \mathrm{CaCl}_{2}, 5.5$ glucose, 20 HEPES; titrated with $\mathrm{NaOH}$ to $\mathrm{pH} 7.5$; total $\mathrm{Na}^{+}=130 \mathrm{~mm}$ was infused by a peristaltic pump at $5 \mu \mathrm{l} / \mathrm{min}$. Because the seal between the pipette tip and the hole in the scala tympani was not leak-proof, the actual perfusion rate was less than the flow rate. During the perfusion, the middle ear cavity was drained with a gauze pad. Only animals in which cochlear thresholds remained within $20 \mathrm{~dB}$ of the predrilling values are included in this report. Pharmacological agents thapsigargin, cyclopiazonic acid (CPA), and ryanodine were obtained from Research Biochemicals (Natick, MA). The drugs were dissolved in the appropriate solvents and diluted in artificial perilymph and loaded into a loop; by turning a valve, the flow of the artificial perilymph could be diverted through the loop containing the drug, thus eliminating any mechanical artifact associated with drug application. The lag between the opening of the valve and the arrival of drug at the ear was estimated by monitoring the appearance of a dye injected into the loop. During the initial set of experiments, this was
$7.5 \mathrm{~min}$ but was later decreased to $5 \mathrm{~min}$ and finally shortened to $3 \mathrm{~min}$. The lag was caused by a fluid dead space between the valve and the inlet hole in the cochlea. The earliest discernible effect of drugs was typically seen after $10 \mathrm{~min}$.

Drugs were perfused through the scala tympani at a single concentration or in increasing doses and then washed out with artificial perilymph. In some experiments, it was possible to test the effect of more than one drug on the same cochlea. The effect of the drug was calculated by measuring the magnitude of the fast and slow effects at a given dose and comparing it with baseline levels, defined as the mean of measurements made for $25 \mathrm{~min}$ before the first dose reached the cochlea. To increase the probability that the measure of the OCB slow effect reflected the maximal effect for a particular dose, only the last data point obtained before the next higher drug concentration reached the cochlea was used. When a single dose was used, the maximal effect before the values returned to baseline levels was used. The response for each drug at each dose was represented as a percentage change in predrug OCB effect, and this change was averaged from a number of animals $(n \geq 4)$. The effect of CPA on the OC effect was tested in 14 animals. Data from two of these animals are not included in this analysis for the following reasons. In one animal (GP 110), three different drugs known to affect the OC effect produced no effect even at high concentrations, suggesting that the cochlea was probably not being perfused adequately. In a second animal (GP 130), there was a negligible (20\%) OC fast effect.

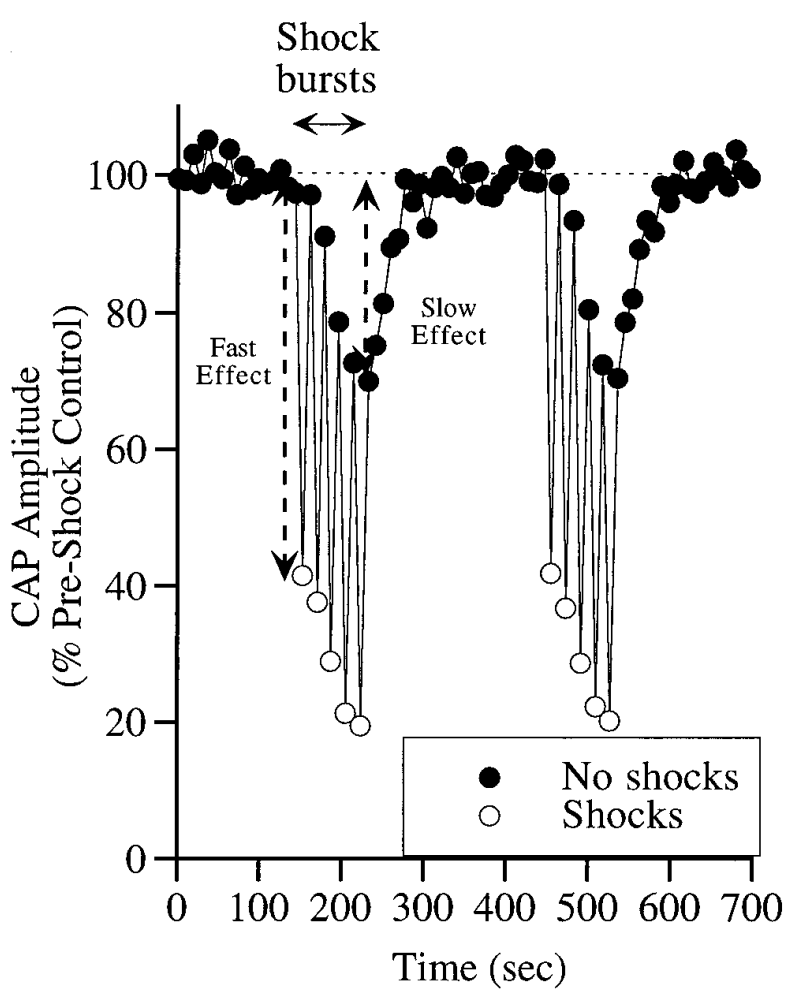

Figure 1. Illustration of the fast and slow effects on the CAP. The fast effect is the decrease in the CAP magnitude to tone pips with shocks compared with the magnitude to tone pips without shocks. The slow effect is seen as the steady decrease in the response to both pips with repeated bursts of shocks. The fast effect is measured by comparing the average of five preshock control CAP (no OCB shocks) values with the CAP amplitude recorded during the first set of OCB shocks: \% suppression $=\left(1-\left(\mathrm{CAP}_{\text {first OCB shock }} / \mathrm{CAP}_{\text {preshock control }}\right)\right) * 100$. The slow effect measure compares the average of the control CAP for the five runs preceding the first set of OCB shock bursts to the control CAP amplitude after the last set of shock bursts: \% suppression $=(1-$ $\left.\left(\mathrm{CAP}_{\text {postshock control }} / \mathrm{CAP}_{\text {preshock control }}\right)\right)^{*} 100$. Acoustic stimuli were tone pips at $14 \mathrm{kHz}$ presented $25 \mathrm{~dB}$ above visual detection threshold. The vertical axis (peak-to-peak CAP amplitude) is normalized to the average value for all measures before the first OCB shocks. 


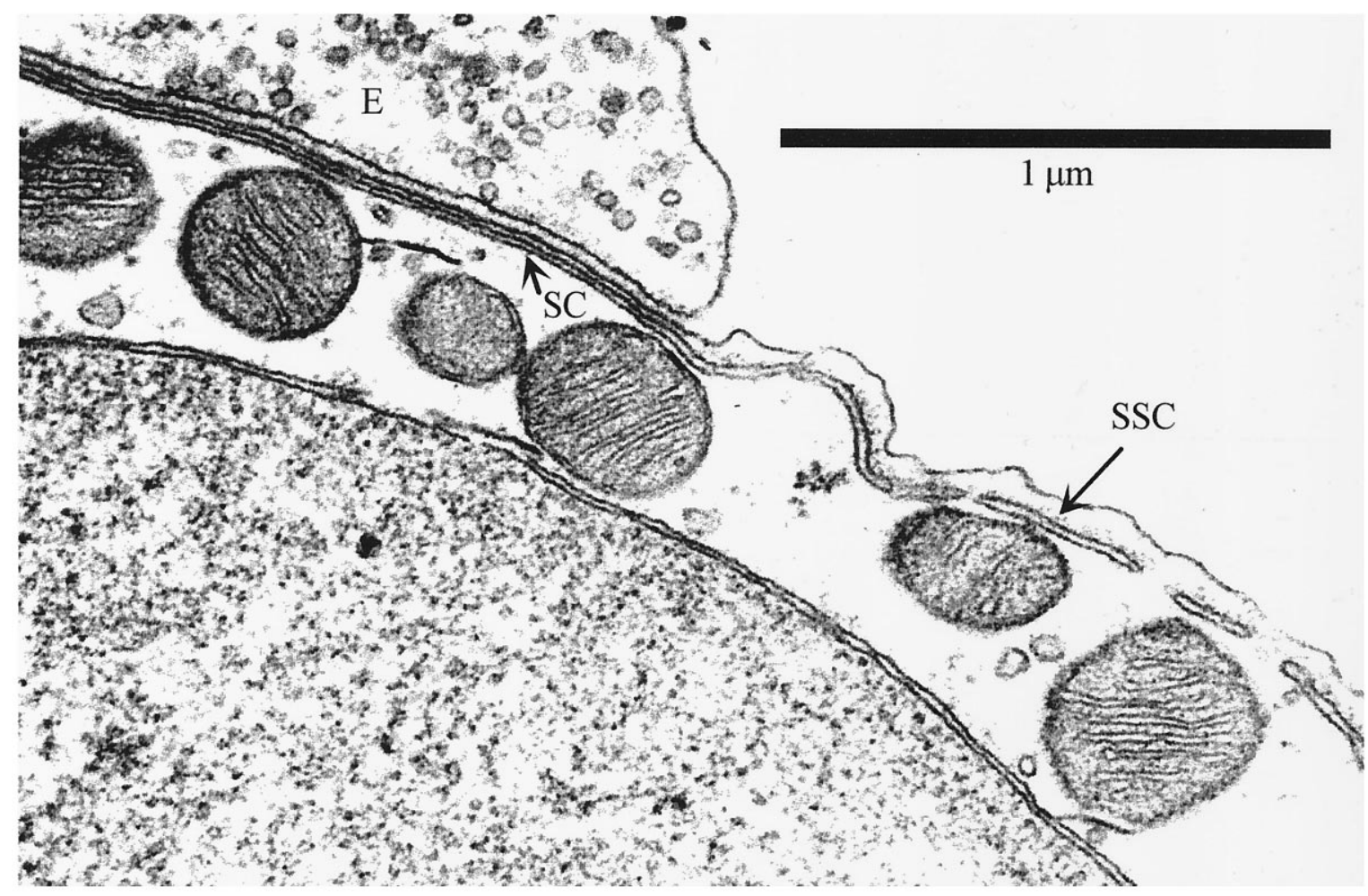

Figure 2. Electron micrograph of the synaptic cisterna (SC) and subsurface cisternae (SSC) in a guinea pig OHC near an OC efferent terminal (E), illustrating the differences between the two cisternae in their relationship to the plasma membrane. In this photograph, the two cisternae appear to be connected, although the more frequent presentation is of two separate adjacent structures. Photograph is courtesy of Dr. Robert Kimura and was published previously (Kimura, 1975).

\section{RESULTS}

One measure of the activity of auditory nerve fibers is the CAP produced in response to a click or a very brief tone pip. As illustrated in Figure 1, activation of efferent fibers of the OCB by electrical shocks suppressed the CAP (open circles) immediately to $\sim 40 \%$ of the preshock control amplitude. The amount of immediate suppression is a measure of the fast effect. With continued shock bursts, there was a gradual decrease in the control CAP (closed circles) to $\sim 70 \%$ of the preshock control. This $30 \%$ suppression of CAP is a measure of the slow effect. When the shocks were turned off after five cycles of shocking, the CAP recovered gradually over $\sim 90$ sec. Thus, the distinguishing features of the slow effect are: (1) the delay in the onset, (2) the gradual suppression of the CAP over 45-90 sec, and (3) the slow recovery over 90-120 sec on cessation of shocks. The time constant of the decay of the slow effect, as measured previously, is $34.4 \pm 8.8 \mathrm{sec}$ (mean $\pm \mathrm{SD}$; $n=9$ ), and the delay between the onset of the fast and the slow effect is $8.5 \pm 5.5 \mathrm{sec}$ (Sridhar et al., 1995). During a typical experimental run, the $80 \mathrm{sec}$ period of intermittent electrical stimulation was followed by a period of $\sim 180 \mathrm{sec}$, during which shocks to the OC fibers were turned off before the next set of shock bursts. With this rate and pattern of stimulation, repeatable slow effects could be obtained over 3-5 hr, the usual duration over which our recordings were made.

\section{Ryanodine can mimic and enhance efferent effects}

Fuchs and Murrow (1992), as well as Blanchet et al. (1996), have suggested that the calcium that enters the OHC through the nicotinic receptor is necessary and sufficient to trigger the rapid hyperpolariza- tion of the $\mathrm{OHC}$ associated with the fast effect. However, a prominent anatomical feature of the efferent synapse is the synaptic cisterna (Saito, 1980), a structure thought to be homologous to the ER (Fig. 2). This structure could amplify the effect of calcium entering through the nicotinic receptor by the process of calcium-induced calcium release (CICR). The elementary calcium signal could then spread to the subsurface cisterna, leading to the buildup of calcium along the baso-lateral cell membrane to produce a slow hyperpolarization. To test this idea, we perfused the scala tympani with ryanodine, a plant alkaloid that affects calcium-release channels present in the ER (Rousseau et al., 1987; Coronado et al., 1994). Although an agonist at low concentrations, ryanodine acts as an antagonist of the calcium-release channels at higher concentrations. In isolated organelles, ryanodine converts from agonist to antagonist at concentrations $>10 \mu \mathrm{M}$ (Rousseau et al., 1987), but in intact cells, in which barriers to diffusion may exist, it has been shown to function as an agonist at concentrations as high as $50 \mu \mathrm{M}$ (Lilly and Gollan, 1995).

When ryanodine was perfused through the scala tympani at concentrations ranging from 30 to $100 \mu \mathrm{M}$, it produced a reversible increase in both the fast and the slow effect. The effect of 30 $\mu \mathrm{M}$ ryanodine on one animal is illustrated in Figure 3. Ryanodine almost doubled the magnitude of the fast effect and increased the magnitude of the slow effect from barely discernible levels to $20 \%$ suppression of the CAP. Both fast and slow effects were increased with ryanodine in a concentration-dependent manner. The percentage changes (mean \pm SE) were as follows. For fast effects, 10 $\mu \mathrm{M}(n=3), 6 \pm 2 \%$; $30 \mu \mathrm{M}(n=8), 25.9 \pm 7.8 \% ; 100 \mu \mathrm{M}(n=$ 5), $27.7 \pm 18.5 \%$. For slow effects, $10 \mu \mathrm{M}(n=3), 9 \pm 10 \%$; $30 \mu \mathrm{M}$ $(n=8), 153 \pm 23.3 \% ; 100 \mu \mathrm{M}(n=5), 368.5 \pm 120.7 \%$. The 

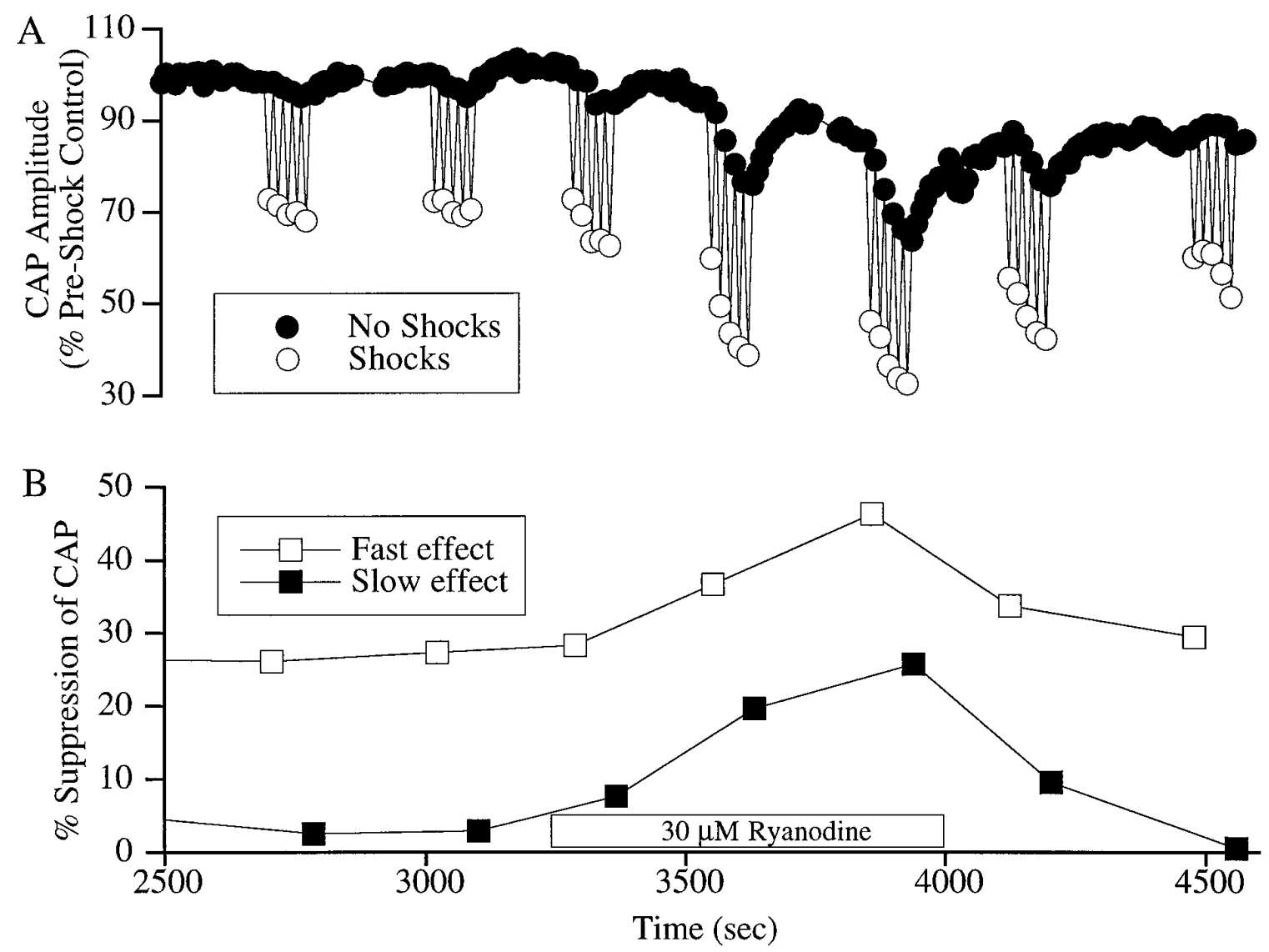

Figure 3. Effect of ryanodine on OC fast and slow effects. $A$, CAP amplitude. $B$, Plot of the computed fast and slow effect at each run. Fast and slow effects were quantified as described in the legend to Figure 1. The box along the time axis indicates the period during which the cochlea was perfused with the drug; at other times, the scala tympani was perfused with artificial perilymph. Ryanodine increased the magnitude of both the fast and slow effects. On washing, these changes were reversed. Acoustic stimuli were clicks presented at $30 \mathrm{~dB}$ above visual detection threshold.

enhancement of efferent effects with ryanodine suggests that CICR may be important in both fast and slow efferent effects.

To ascertain that the effect of ryanodine was via an action on the OHCs, the CM was monitored. The CM is a potential that represents the summed receptor potentials and is generated largely by the OHCs (Dallos and Cheatham, 1976). It is known that stimulation of the efferents enhances the CM (Fex, 1959), presumably by increasing the conductance of the OHC membrane to hyperpolarize the cell (Fex, 1967). This enhancement would be most pronounced at low frequencies, at which the membrane conductance determines the transmembrane potential, but less pronounced at high frequencies, at which membrane capacitance is more important (Guinan, 1996; Murugasu and Russell, 1996a). We have demonstrated previously that the slow suppression of the CAP is mirrored by an increase in the CM (Sridhar et al., 1995). If ryanodine were acting at the $\mathrm{OHCs}$, one would expect an enhancement of the fast and slows effects on CM. As illustrated in Figure 4, the pre-ryanodine CM measurement shows a good fast effect on CM but no measurable slow effect. Ryanodine produced increases in both fast and slow effects on CM, which disappeared on washing out the drug, consistent with the idea that the effect of ryanodine was attributable to an increase in the conductance of OHCs.

In addition to its enhancement of the fast and slow effects on CAP and CM, ryanodine decreased the baseline CAP in a dosedependent manner. The decrease was small, although noticeable

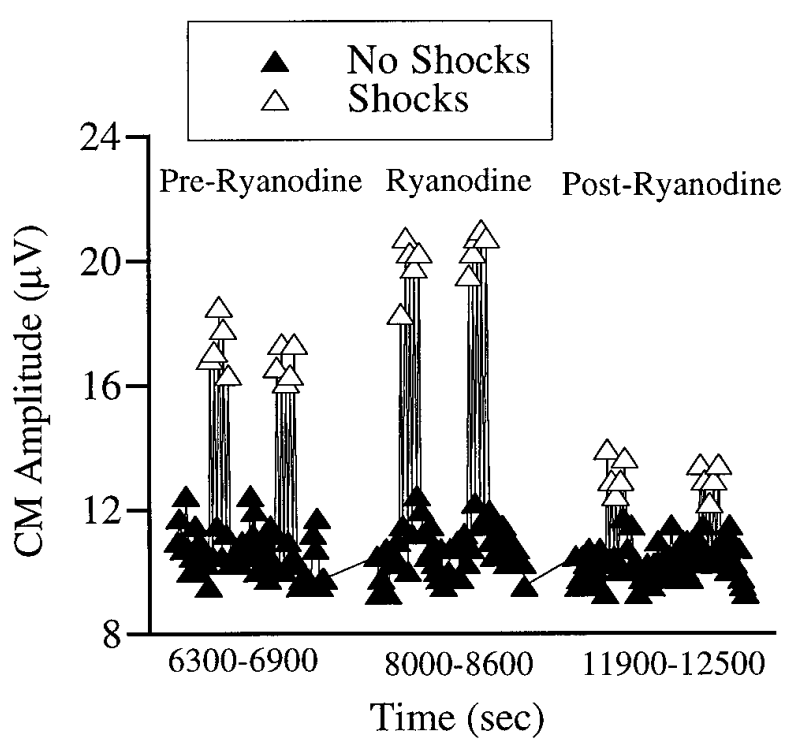

Figure 4. Effect of ryanodine on CM. Ryanodine increased the magnitude of both the fast and the slow effects on CM. On washing, these changes were reversed. Although $\mathrm{CM}$ was not routinely monitored because higher acoustic stimulus levels are required, similar results were seen in four perfusions in two animals in which CM was monitored, including those presented in Figure 5. Acoustic stimuli were clicks presented at $30 \mathrm{~dB}$ above visual detection threshold. 

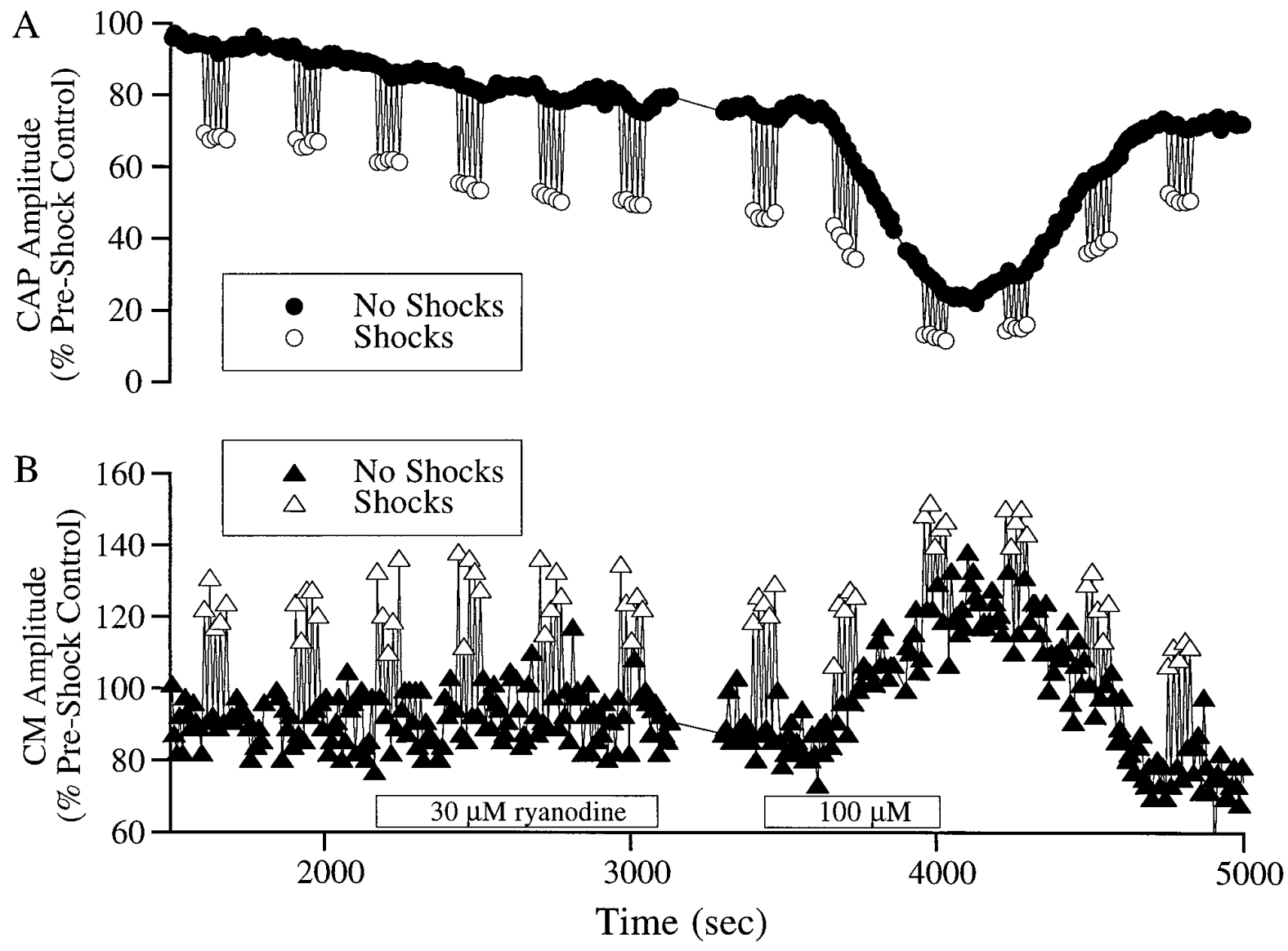

Figure 5. Effect of ryanodine on CM and CAP. $A$ and $B$ are records of normalized CAP and CM amplitude in a case that produced marked decrease in the CAP. Baseline data were taken while the scala tympani was perfused with artificial perilymph. The boxes along the time axis indicate the period during which the cochlea was perfused with the drug. The acoustic stimulus was $30 \mathrm{~dB}$ above threshold to produce a measurable CM. Obviously, accurate measurement of the slow effect is difficult in the face of such large changes in the CAP.

in Figure 3, but much larger effects could be seen in some preparations, such as that illustrated in Figure $5 A$. The decrease in CAP could have been attributable to actions of ryanodine on any structure involved in the generation of the auditory nerve response. However, a decrease in the amplitude of the CAP is a plausible consequence of an agonist of CICR. That is, one might bypass the ACh receptor and release calcium from the subsurface cisternae directly. The end result on the $\mathrm{OHC}$ would be the same. If this were so, then the suppression of CAP by ryanodine should be accompanied by an increase in the amplitude of the CM. As shown in Figure $5 B$, the decrease in the CAP was accompanied by an increase in the $\mathrm{CM}$, suggesting that the decrease in the CAP is probably attributable to a hyperpolarization of the OHCs and a consequent decrease in the amplification of basilar membrane motion.

\section{CPA, a SERCA antagonist, enhances the slow effect}

Electron microscopic evidence (Saito, 1980), as well as labeling isolated OHCs with specific lipids (Pollice and Brownell, 1993), have suggested that the synaptic and subsurface cisternae are similar to the ER. Usually, these membranes are studded with SERCA that buffer cytoplasmic calcium levels by transporting calcium into the reticulum (Heilmann et al., 1984). To determine the role of SERCA in buffering increases in cytoplasmic calcium during efferent action in OHCs, we perfused CPA, a SERCA antagonist (Seidler et al., 1989), through the scala tympani. At a concentration of $10 \mu \mathrm{M}, \mathrm{CPA}$ increased the magnitude of the slow effect without altering the fast effect (Fig. 6). CPA produced a fourfold increase in the magnitude of the slow effect (from 10 to $40 \%$ ), which returned to baseline value on washing out the drug. In the seven animals that were treated with $10 \mu \mathrm{M}$ CPA, the slow effect increased by an average of $230 \pm 104 \%$ (mean \pm SEM).

CPA did produce a small but noticeable $(10 \%)$ decrease in the baseline CAP values at a concentration of $10 \mu \mathrm{M}$. When the concentration was increased to $25 \mu \mathrm{M}$, CPA, like ryanodine, produced additional effects. These included an increase in the amplitude of the fast effect and a profound depression of the baseline CAP (data not shown).

Another SERCA inhibitor that has been used extensively is thapsigargin (Thastrup et al., 1990), which can block SERCA at nanomolar concentrations. Thapsigargin was perfused through the scala tympani at concentrations ranging from $100 \mathrm{nM}$ to $1 \mu \mathrm{M}$. In the four animals tested, thapsigargin selectively increased the magnitude of the slow effect by $72 \pm 15 \%(47 \%$ at $100 \mathrm{~nm}, 97 \%$ at $1 \mu \mathrm{M})$, whereas its effect on the fast effect was negligible $(8 \pm$ $3 \%$ ). The fact that SERCA antagonists selectively enhance the slow effect without altering the fast effect suggests that SERCA is important in removing calcium from a compartment distinct from the synaptic region.

\section{CPA blocks diminution of the slow effect}

One of the features of the slow effect was a diminution on longer periods of OCB shocks. As shown in Figure $7 A$, when electrical 

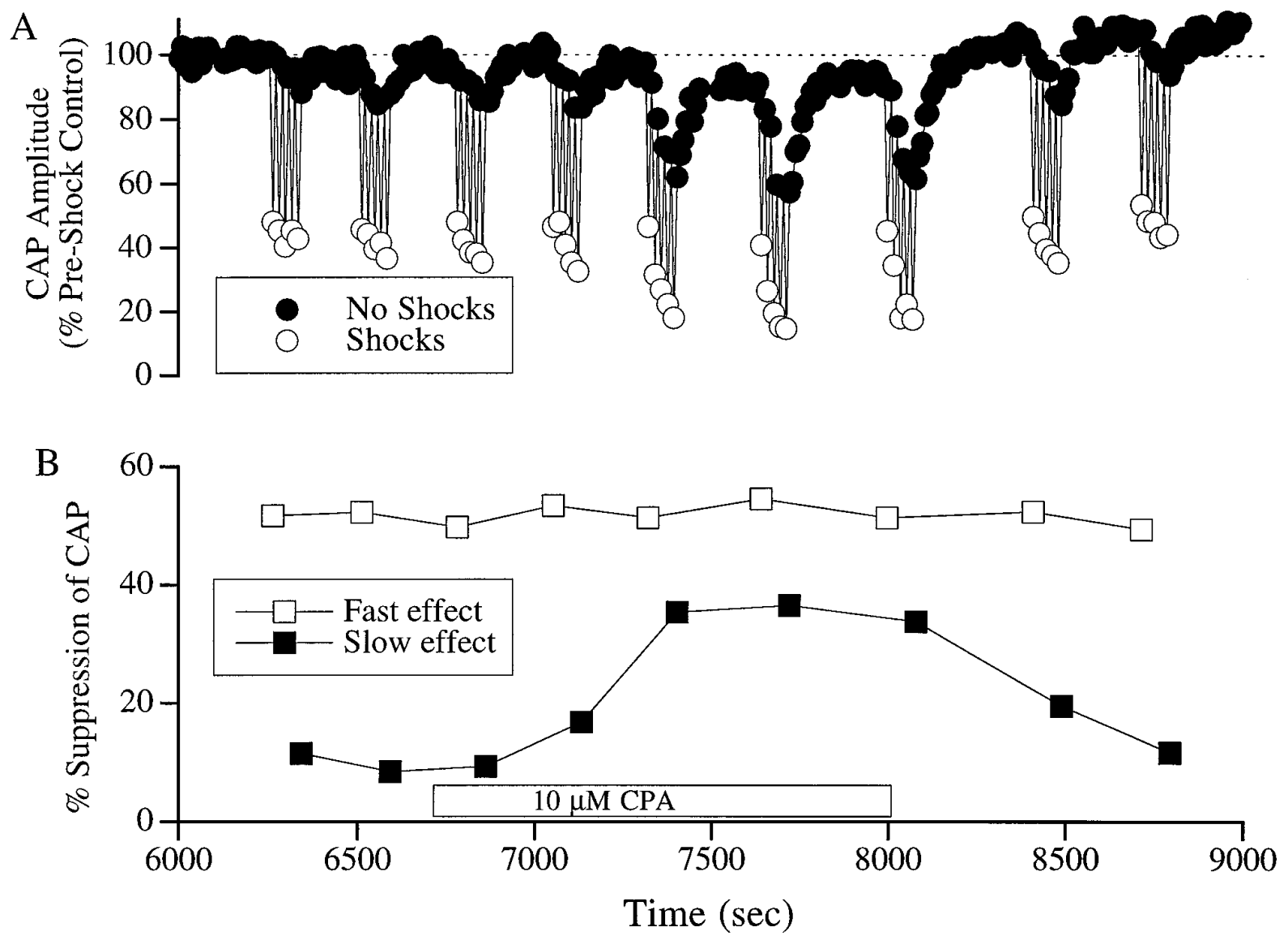

Figure 6. Effect of CPA on OC fast and slow effects. $A$ shows the CAP values normalized to preshock control values. $B$ is a plot of the computed fast and slow effects at each run. Fast and slow effects were quantified as described in the legend to Figure 1 . The box along the time axis indicates the period during which the cochlea was perfused with the drug. CPA increased the magnitude of the slow effect without altering the fast effect. On washing, these changes were reversed. Stimuli were $14 \mathrm{kHz}$ tone pips presented at $25 \mathrm{~dB}$ above visual detection threshold.

stimulation was prolonged from 80 to $300 \mathrm{sec}$, the slow suppression of the CAP began to wane in the face of continuous shock bursts after reaching a maximum at $\sim 90-100 \mathrm{sec}$. To quantify this diminution and compare it across experiments, an exponential curve was fit to the data points representing the control CAP values between 100 and $300 \mathrm{sec}(A)$. The time constant of the diminution was $460 \pm 180 \mathrm{sec}($ mean $\pm \mathrm{SD} ; n=9)$.

CPA produced a marked decrease in the diminution (as seen by an increase in the time constant) of the slow effect (Fig. 7B), which returned to predrug values on washing out the drug. All five cases had lengthened time constants: three showed more than twofold increases in the time constant of diminution, whereas in two cases, the CAP magnitude continued to decrease over the entire $300 \mathrm{sec}$ period of OCB stimulation (showing no diminution of the slow effect at all).

\section{CPA induces the slow effect in frequency regions where it is not normally seen}

An important difference between the OC fast and slow effects is their frequency distribution. Whereas fast effects peak for responses to frequencies between $\sim 6$ and $10 \mathrm{kHz}$ (Gifford and Guinan, 1987), slow effects are minimal below $10 \mathrm{kHz}$ and peak for responses between 14 and $17 \mathrm{kHz}$ (Sridhar et al., 1995). Although a number of structures and substances exhibit systematic gradients along the cochlear partition, it is not clear which of these, if any, is responsible for the variation in the distribution of the two efferent effects. To examine whether a decrease in calcium buffering would permit a spread of the slow effect to lower frequencies, CPA was perfused through the cochlea while monitoring the slow effect at $8 \mathrm{kHz}$. CPA increased the slow effect at 14 $\mathrm{kHz}$ from $22 \pm 9 \%$ to $62 \pm 11 \%$ suppression of CAP amplitude. In addition, it produced an increase in the slow effect at $8 \mathrm{kHz}$ from $7 \pm 2 \%$ to $50 \pm 10 \%$ suppression of CAP amplitude (data averaged from six animals).

\section{DISCUSSION}

OC fibers provide feedback inhibition to the cochlea, which is manifest over two time scales that are three orders of magnitude apart. In a previous report (Sridhar et al., 1995), we presented evidence that both the fast and the slow effects are mediated by the release of $\mathrm{ACh}$ from the medial OC fibers acting on the same nicotinic ACh receptor on the OHCs of the cochlea. This suggests that the difference in their temporal profiles must be a function of distinct postsynaptic mechanisms. The present finding that the slow effect can be enhanced by ryanodine, $\mathrm{CPA}$, and thapsigargin, agents that tend to increase the cytoplasmic free calcium level, suggests that the second messenger for the slow effect is calcium. If so, an attractive hypothesis is that calcium is producing the slow effect by activating $\mathrm{K}_{\mathrm{Ca}}$ channels, as has been shown for the fast effect. If calcium is also the messenger for the fast effect, then how 

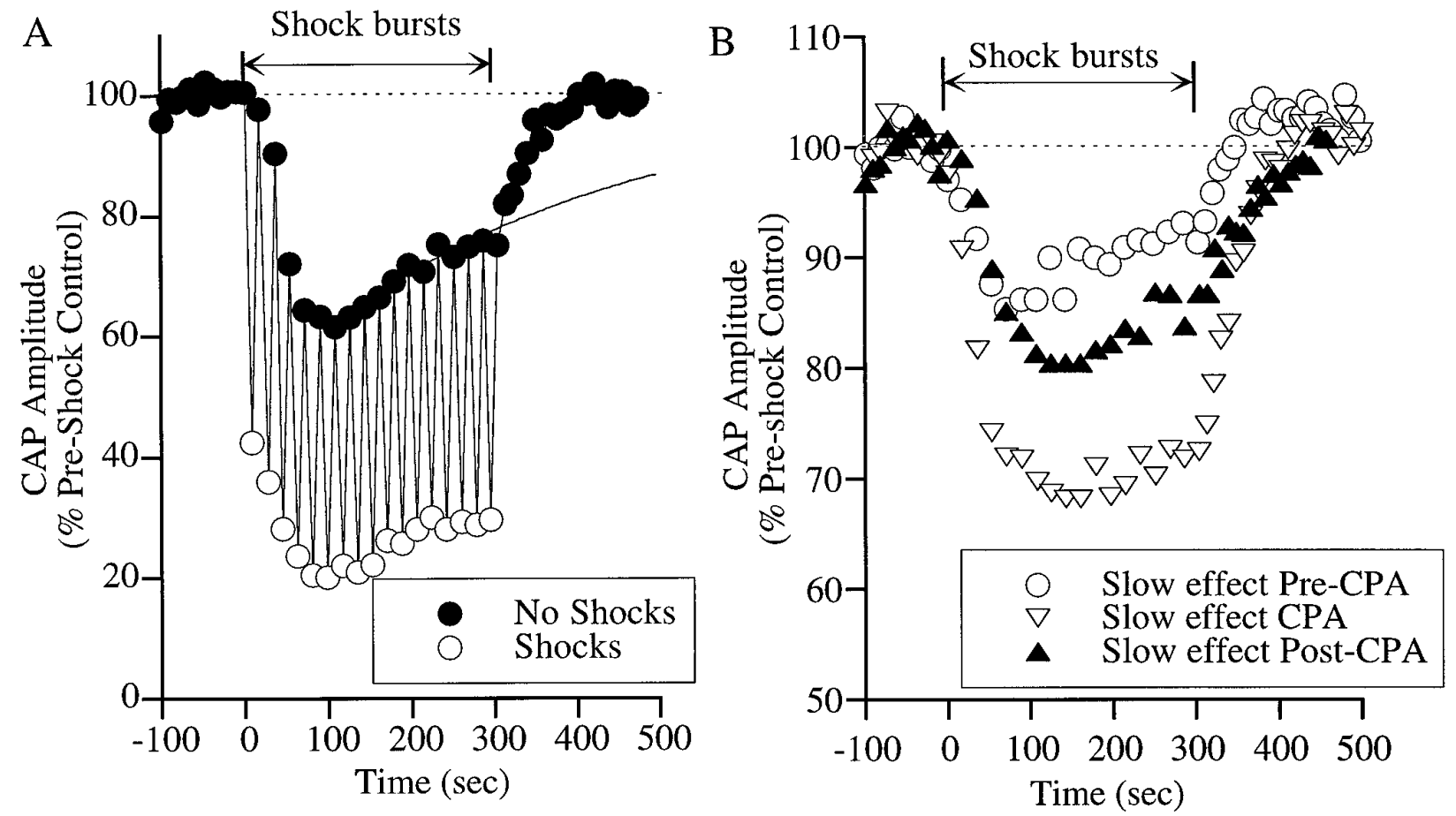

Figure 7. Fast and slow effects on CAP amplitude during several minutes of OCB stimulation. An exponential curve was fit to the data points representing the CAP values with no shocks between 100 and $300 \mathrm{sec}$. The time constant was $460 \pm 180 \mathrm{sec}$ (mean \pm SD). The acoustic stimuli were clicks presented at $25 \mathrm{~dB}$ above threshold. All other aspects of data collection and display are as described for Figure 1. $B$, Diminution of the slow effect before, during, and after CPA perfusion. The time constants for diminution of the slow effect for the curves taken before, during, and after CPA, respectively, were 376,1462 , and $497 \mathrm{sec}$.

does calcium entering into the efferent postsynaptic space activate $\mathrm{K}_{\mathrm{Ca}}$ channels over two time scales? We propose that the mechanism by which the $\mathrm{OHC}$ achieves dual temporal switching with a single second messenger (calcium) is by the unique arrangement of subcellular structures in the efferent synaptic region.

\section{Hypothesis for generation of OC fast and slow effects}

Our hypothesis is based on the results of our pharmacological experiments and the unusual microanatomy of the $\mathrm{OHC}$ efferent subsynaptic region (Saito, 1980). As illustrated in Figure 2, directly opposite each medial OC synapse and beneath the plasma membrane of the $\mathrm{OHC}$ is a single flattened sac, the synaptic cisterna, confining a cytoplasmic space $8-10 \mathrm{~nm}$ wide. The synaptic cisterna is either connected to or in close apposition to the subsurface cisternae, a multilayered stack of membranous sacs lining the sides of OHCs; the outermost subsurface cisterna is placed at a distance of $35-40 \mathrm{~nm}$ from the plasmalemma, creating a cytoplasmic space between the plasma membrane and the cisterna at least fourfold greater than the subsynaptic space.

We envision a sequence of events that lead to the fast and slow effects, which we present schematically in Figure 8. Our view elaborates on a well-established hypothesis for the generation of the fast cholinergic effects (Housley and Ashmore, 1991; Fuchs and Murrow, 1992), which argues that ACh released from the OC terminal binds to the nicotinic receptor and permits a brief inward calcium current. The entering calcium can activate $\mathrm{K}_{\mathrm{Ca}}$ channels localized at the synapse leading to an outward $\mathrm{K}^{+}$current and hyperpolarization of the OHC. The calcium is buffered within $400 \mathrm{msec}$, and the OHC membrane potential reverts to its resting level. We argue, based on the ability of ryanodine to increase the fast effect, that this inward calcium spike can be amplified by ryanodine receptors on the synaptic cisterna by a CICR process. Slow effects arise when persistent entry of calcium through the receptor (as occurs during prolonged stimulation of the OC fibers) leads to multiple elementary calcium events that gradually spread to the subsurface cisternae, releasing calcium from it. Calcium that accumulates beneath the baso-lateral cell membrane activates additional $\mathrm{K}_{\mathrm{Ca}}$ channels that are remote from the synapse leading to the slow hyperpolarization that underlies the slow effect. These remote $\mathrm{K}_{\mathrm{Ca}}$ channels may be maxi- $\mathrm{K}_{\mathrm{Ca}}$ channels reported to exist on hair cells spatially segregated from the efferent synapse (Blanchet et al., 1996). The buildup and buffering of calcium along the subsurface cisternae are much slower because of multiple factors probably including the fourfold increase in volume and the differential distribution of buffer components. We are not suggesting that the only function of the subsurface cisternae is to mediate the slow effect, but rather, that the hair cell makes advantageous use of the close juxtaposition of this large membranous network and the efferent synapse.

\section{Synaptic cisterna and CICR}

That ryanodine enhances both the fast and the slow effects confirms the presence of these calcium-release channels in the OHC. The synaptic and subsurface cisternae are probable sites. The dramatic increase in CM accompanying the drop in CAP produced by $100 \mu \mathrm{M}$ ryanodine indicates that ryanodine brings about its effect by increasing the conductance of OHCs. The increase in $\mathrm{OHC}$ conductance is probably a consequence of the opening of 


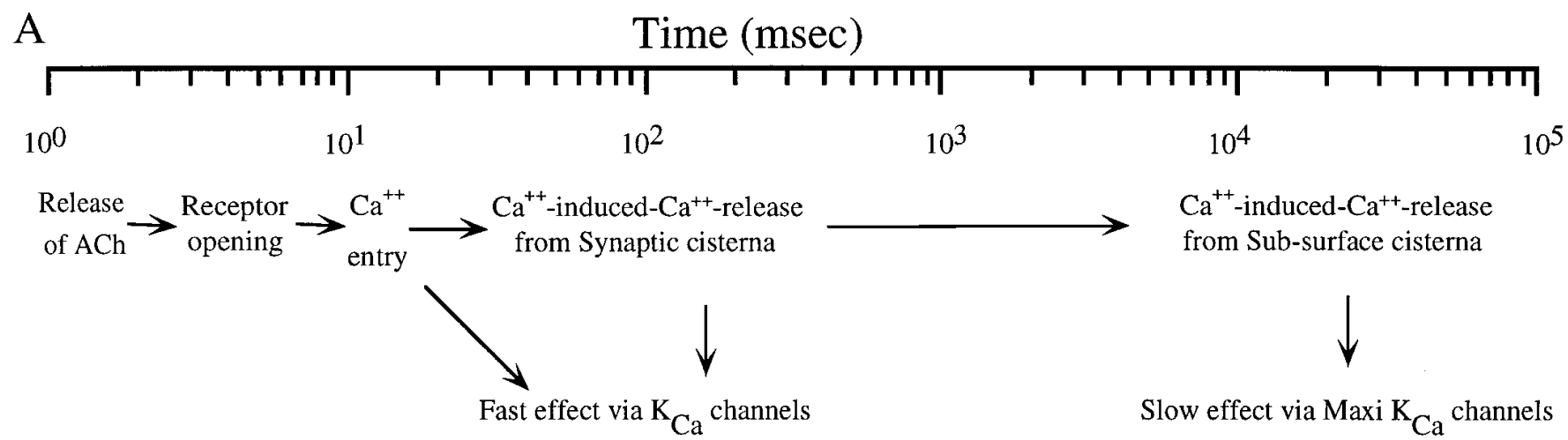

B

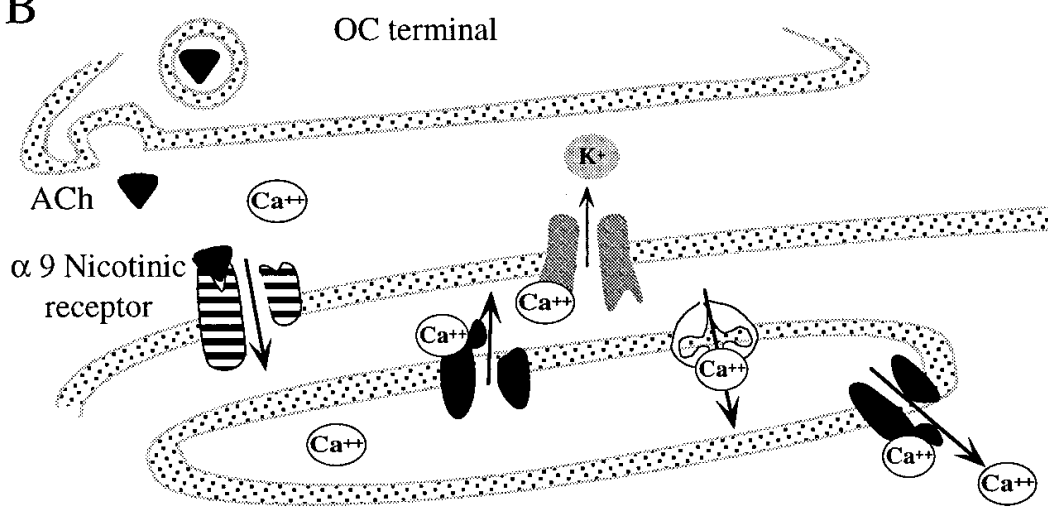

Synaptic cisterna

\section{Outer Hair Cell}

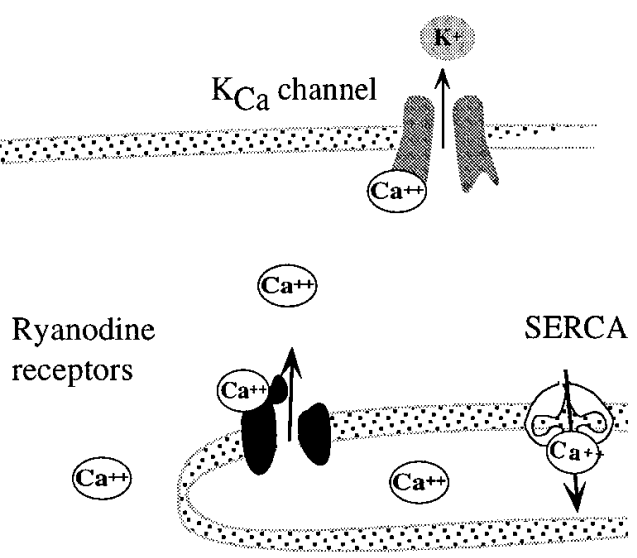

Sub-surface cisterna

Figure 8. Hypothesis for the generation of OC fast and slow effects. $A$, Flow chart of events on a log time scale. $B$, Spatial arrangement of the subcellular components at the OC synapse with the OHC. Only the dimensions of the synaptic cleft and the spaces between the cell membrane and the cisternae are drawn to scale.

$\mathrm{K}_{\mathrm{Ca}}$ channels, which in turn is attributable to the raised calcium concentration produced by ryanodine.

The amplification of the fast effect by ryanodine argues for a CICR component to the fast effect. Whereas Martin and Fuchs (1992) and Blanchet et al. (1996) have suggested that the entry of external calcium is sufficient to trigger the fast effect, our evidence suggests that in vivo CICR may add to the effect. However, we cannot assess the relative contributions of the external versus internal calcium, because we have not blocked the ryanodine receptor in these experiments. Our data assign the role of a molecular amplifier to the synaptic cisterna.

This argument is supported by the striking similarity between the modus operandi of hyperpolarizing the $\mathrm{OHC}$ and cerebral arterial smooth muscle cell (Nelson et al., 1995). In cerebral arterial smooth muscle cells, entry of calcium through voltagegated $\mathrm{Ca}^{2+}$ channels leads to CICR from the sarcoplasmic reticulum apposed to the cell membrane and subsequent hyperpolarization attributable to an outward $\mathrm{K}^{+}$current through $\mathrm{K}_{\mathrm{Ca}}$ channels. The hyperpolarization is reversed by the buffering of calcium by SERCA (Fay, 1995; Nelson et al., 1995). Thus, except for the voltage-gated calcium channels, the other components and the structural motif may be similar between the arterial smooth muscle cell and the OHC. The novel arrangement at the $\mathrm{OHC}$ efferent synapse is the juxtaposition of the subsurface cisternae and the synaptic cisterna, permitting a slow spread of calcium release.

\section{Role of SERCA in OC effects}

The results of our experiments with SERCA antagonists support the idea that the slow effect is mediated by an increase in the cytosolic calcium concentration. The fact that it is possible to selectively increase the magnitude of the slow effect by using SERCA antagonists at low doses suggests that SERCA plays a dominant role in the buffering of calcium that builds up between the subsurface cisternae and the plasma membrane. The enhancement of the fast effect at $30 \mu \mathrm{M} \mathrm{CPA}$ argues for the presence of SERCA in the synaptic cisterna, albeit as a secondary component in the buffering of calcium at the synapse.

The fact that the fast effect does not diminish in the face of continuous OC stimulation suggests that the diminution of the slow effect is not attributable to adaptation of the nicotinic receptor. The block of the diminution of the slow effect in the presence of SERCA antagonists implicates $\mathrm{Ca}^{2+}$-ATPase as the agent responsible for diminution. It is possible to diminish or abolish the slow effect with long periods of OC stimulation (Reiter and Liberman, 1995; Sridhar et al., 1995), indicating that the degree and rate of diminution of the slow effect are dependent on the duration and rate of OC stimulation. One 
mechanism by which SERCA activity is upregulated might be phosphorylation of the enzyme by a calcium-dependent kinase (Xu et al., 1993).

\section{Comparison to recent experiments on acetylcholine action on basilar membrane motion}

Murugasu and Russell (1996b) have shown that acetylcholine infused through the scala tympani can elevate thresholds for displacement of the basilar membrane. Presumably, the acetylcholine activates the nicotinic receptor, hyperpolarizes OHCs, and decreases the amplification of basilar membrane motion. In their experiments (Murugasu and Russell, 1996b), CPA has been shown to enhance the effects of applied acetylcholine on basilar membrane displacement in guinea pig cochleas, consistent with the results we present here. Also reported was an irreversible antagonistic action of $100 \mu \mathrm{M}$ ryanodine on the action of acetylcholine. In contrast, we observed dosedependent enhancement of both fast and slow effects by ryanodine at concentrations of 30-100 $\mu \mathrm{M}$. Perhaps this difference can be accounted for by the dose-dependent change in action of ryanodine from agonist to antagonist, if the concentration of ryanodine at the site of basilar membrane measurement made by Murugasu and Russell (very near the perfusion inlet hole) is higher than the concentrations of ryanodine at the site of our measurement of CAP response to clicks (more apical from the perfusion inlet).

\section{Functional consequences and general significance}

Reiter and Liberman (1995) have provided convincing evidence that protection against temporary threshold shifts caused by high-level tones is correlated with the OC slow effect and not the fast effect. How might the slow effect protect the cochlea? It is unlikely to be the hyperpolarization per se, because even the greater hyperpolarization assumed to be associated with the fast effect does not provide protection. It is plausible that calcium, in addition to opening the $\mathrm{K}^{+}$channels, activates other effector proteins that lead to distinct biochemical alterations in the OHC. Such a mechanism might lead to the decrease in OHC stiffness that results from acetylcholine application (Dallos et al., 1996). This decrease in stiffness may play a key role in protecting the $\mathrm{OHC}$ from damage caused by high-level sound. Viewed this way, the hyperpolarization and resultant suppression of the CAP is an epiphenomenon, and the critical events for protection are the activation of unknown alternate effectors by calcium. If, indeed, the slow effect and protection from acoustic overstimulation are correlated, it should be possible to enhance protection and spread its frequency range by using CPA, an agent that spreads the distribution of the slow effect and enhances its magnitude.

Varying the temporal structure of signals is a recurring theme in cellular communication. A ubiquitous implementation of this principle is the evolution of two kinds of cell surface receptors for extracellular ligands: ionotropic receptors that produce their cellular effects within a few milliseconds and metabotropic receptors that require tens of milliseconds to seconds. Our findings suggest that OHCs use a single receptor to produce both rapid and long-term effects by using the second messenger calcium. This is yet another example of the complex spatio-temporal signaling by calcium (Bootman and Berridge, 1995; Clapham, 1995). Our hypothesis suggests that this dual effect arises via the unique microanatomy of the $\mathrm{OHC}$, thus providing a functional role for the unusual ultrastructure of this cell: the synaptic and subsurface cisternae. Similar specializations that have been observed in neurons (Rosenbluth, 1962; Henkart et al., 1976; Duce and Keen, 1978; Henkart, 1980) might function in analogous ways. Whereas the biochemical approach to cell-signaling has focused on the molecular components, our findings underscore the need to examine signaling pathways using intact cells, if one is to uncover effects arising from spatial segregation of signaling components.

\section{REFERENCES}

Blanchet C, Erostegui C, Sugasawa M, Dulon D (1996) Acetylcholineinduced potassium current of guinea pig outer hair cells: its dependence on a calcium influx through nicotinic-like receptors. $J$ Neurosci 16:2574-2584.

Bootman MD, Berridge MJ (1995) The elemental principles of calcium signaling. Cell 83:675-678.

Brown MC, Nuttall AL, Masta RI (1983) Intracellular recordings from cochlear inner hair cells: effects of stimulation of the crossed olivocochlear efferents. Science 222:69-72.

Clapham DE (1995) Calcium signaling. Cell 80:259-268.

Coronado R, Morrissette J, Sukhareva M, Vaughan DM (1994) Structure and function of ryanodine receptors. Am J Physiol 266:1485-1504.

Dallos P (1992) The active cochlea. J Neurosci 12:4575-4585.

Dallos P, Cheatham MA (1976) Production of cochlear potentials by inner and outer hair cells. J Acoust Soc Am 60:510-512.

Dallos P, He DZZ, Lin X, Evans BN, Sziklai I (1996) Efferent control of cochlear mechanics: outer hair cells. Abstracts from "Diversity in auditory mechanics." Berkeley, June 24-28.

Duce IR, Keen P (1978) Can neuronal smooth endoplasmic reticulum function as a calcium reservoir? Neuroscience 3:837-848.

Elgoyhen AB, Johnson DS, Boulter J, Vetter DE, Heinemann S (1994) Alpha 9: an acetylcholine receptor with novel pharmacological properties expressed in rat cochlear hair cells. Cell 79:705-715.

Erostegui C, Norris CH, Bobbin RP (1994) In vitro pharmacologic characterization of a cholinergic receptor on outer hair cells. Hear Res 74:135-147.

Fay FS (1995) Calcium sparks in vascular smooth muscle: relaxation regulators. Science 270:588-589.

Fex J (1959) Augmentation of cochlear microphonic by stimulation of efferent fibers in the cat. Acta Otolaryngol (Stockh) 50:540-541.

Fex J (1967) Efferent inhibition in the cochlea related to hair-cell activity: study of postsynaptic activity of crossed olivocochlear fibres in the cat. J Acoust Soc Am 41:666-675.

Fuchs PA, Murrow BW (1992) Cholinergic inhibition of short (outer) hair cells of the chick's cochlea. J Neurosci 12:800-809.

Galambos R (1956) Suppression of auditory nerve activity by stimulation of efferent fibers to cochlea. J Neurophysiol 19:424-437.

Gifford ML, Guinan Jr JJ (1983) Effects of crossed-olivocochlear-bundle stimulation on cat auditory nerve fiber responses to tones. J Acoust Soc Am 74:115-123.

Gifford ML, Guinan Jr JJ (1987) Effects of electrical stimulation of medial olivocochlear neurons on ipsilateral and contralateral cochlear responses. Hear Res 29:179-194.

Guinan Jr JJ (1996) Efferent inhibition as a function of efferent stimulation parameters and sound frequency: testing the OHC-shunt hypothesis. In: Diversity in auditory mechanics (Lewis WR, Long GR, Lyon RF, Narins PM, Steele CR, eds). Singapore, NJ: World Scientific.

Heilmann C, Spamer C, Gerok W (1984) The calcium pump in rat liver endoplasmic reticulum. J Biol Chem 259:11139-11144.

Henkart M (1980) Identification and function of intracellular calcium stores in axons and cell body neurons. Fed Proc 39:2783-2789.

Henkart M, Landis DMD, Reese TS (1976) Similarity of junctions between plasma membranes and endoplasmic reticulum in muscle and neurons. J Cell Biol 70:338-347.

Housley GD, Ashmore JF (1991) Direct measurement of the action of acetylcholine on isolated outer hair cells of the guinea pig cochlea. Proc R Soc Lond [Biol] 244:161-167.

Kakehata S, Nakagawa T, Takasaka T, Akaike N (1993) Cellular mechanism of acetylcholine induced response in dissociated outer hair cells of guinea-pig cochlea. J Physiol (Lond) 463:227-244.

Kiang NYS, Watanabe T, Thomas EC, Clark LF (1965) Discharge patterns of single fibers in the cat's auditory nerve. Cambridge, MA: MIT. 
Kimura R (1975) The ultrastructure of the organ of Corti. Int Rev Cytol 42:173-222.

Lilly LB, Gollan JL (1995) Ryanodine-induced calcium release from hepatic microsomes and permeabilized hepatocytes. Am J Physiol 268:G1017-1024.

Murugasu E, Russell IJ (1996a) The effect of efferent stimulation on basilar membrane displacement in the basal turn of the guinea pig cochlea. J Neurosci 16:325-332.

Murugasu E, Russell IJ (1996b) The role of calcium on the effects of intracochlear acetylcholine perfusion on basilar membrane displacement in the basal turn of the guinea pig cochlea. Auditory Neurosci 2:363-376.

Nelson MT, Cheng H, Rubart M, Santana LF, Bonev AD, Knot HJ, Lederer WJ (1995) Relaxation of arterial smooth muscle by calcium sparks. Science 270:633-637.

Pollice PA, Brownell WE (1993) Characterization of the outer hair cell's lateral wall membranes. Hear Res 70:187-196.

Reiter ER, Liberman MC (1995) Efferent mediated protection from acoustic overexposure: relation to "slow" effects of olivocochlear stimulation. J Neurophysiol 73:506-514.

Rosenbluth J (1962) Subsurface cisterns and their relationship to the neuronal plasma membrane. J Cell Biol 13:405-421.

Rousseau E, Smith JS, Meissner G (1987) Ryanodine modifies conduc- tance and gating behaviour of single calcium release channels. Am J Physiol 253:c364-c368.

Saito K (1980) Fine structure of the sensory epithelium of the guinea pig organ of Corti: afferent and efferent synapses of hair cells. J Ultrastruct Res 71:222-232.

Seidler NW, Jona I, Vegh M, Martonosi A (1989) Cyclopiazonic acid is a specific inhibitor of the $\mathrm{Ca}^{2+}$-ATPase of sarcoplasmic reticulum. J Biol Chem 264:17816-17823.

Sridhar TS, Brown MC, Liberman MC, Sewell WF (1995) A novel cholinergic "slow effect" of efferent stimulation on cochlear potentials in the guinea pig. J Neurosci 15:3667-3678.

Thastrup O, Cullen PJ, Drobak BJ, Hanley MR, Dawson AP (1990) Thapsigargin, a tumor promoter, discharges intracellular $\mathrm{Ca}^{2+}$ stores by specific inhibition of the endoplasmic reticulum $\mathrm{Ca}^{2+}$-ATPase. Proc Natl Acad Sci USA 87:2466-2470.

Warr WB (1992) Organization of olivocochlear efferent systems in mammals. In: The mammalian auditory pathway: neuroanatomy (Webster DB, Popper AN, Fay RR, eds), pp 410-448. New York: Springer.

White JS, Warr WB (1983) The dual origins of the olivocochlear bundle in the albino rat. J Comp Neurol 219:203-214.

$\mathrm{Xu}$ A, Hawkins C, Narayanan N (1993) Phosphorylation and activation of the $\mathrm{Ca}^{2+}$ pumping ATPase of cardiac sarcoplasmic reticulum by $\mathrm{Ca}^{2+} /$ calmodulin-dependent protein kinase. J Biol Chem 268: 8394-8397. 